\title{
Pathways to Pain and Disability: the Impact of Early Social Deprivation and Educational Attainment in Newly Diagnosed Osteoarthritis Patients
}

Afroditi Kouraki ( $\square$ afroditi.kouraki@nottingham.ac.uk)

University of Nottingham https://orcid.org/0000-0002-5976-9047

\section{Tobias Bast}

University of Nottingham

\section{Eamonn Ferguson}

University of Nottingham

\section{Ana M. Valdes}

University of Nottingham

\section{Research article}

Keywords: Osteoarthritis, Independence, Pain, Deprivation, Education, Anxiety, Cognition, Longitudinal

Posted Date: February 26th, 2021

DOI: https://doi.org/10.21203/rs.3.rs-247989/v1

License: (9) (1) This work is licensed under a Creative Commons Attribution 4.0 International License. Read Full License 


\section{Abstract}

\section{Background}

Links between pain and cognitive function on one hand and pain and anxiety on the other have already been shown in other studies and there is biological evidence linking osteoarthritis to educational attainment. However, the inter-play of these factors and the role of key social (social deprivation) factors at the early disease stages are not understood. Therefore, we tested how social deprivation, education and anxiety, before diagnosis, affects the cognition, pain and independence (activities of daily living) relationship longitudinally after diagnosis of osteoarthritis.

\section{Methods}

Using data from waves 4, 5, 6 and 7 of the Survey of Health, Ageing and Retirement in Europe (SHARE) ( $n=$ 1,240), we examined the impact of social deprivation, education and anxiety on the dynamic relationship between cognitive function, pain and instrumental activities of daily living (IADL) in a subsample of respondents reporting a diagnosis of osteoarthritis at wave 6 , with cross-lagged panel models.

\section{Results}

Social deprivation before diagnosis predicted poorer cognitive function and higher pain levels after diagnosis, and further predicted impairments in IALD at wave 7 through its negative effect on cognitive function at wave 6 . Education before diagnosis was protective against impairments in daily living after diagnosis via better cognitive function and lower anxiety at wave 5 .

\section{Conclusion}

We show for the first time that social deprivation, before osteoarthritis diagnosis, predicts functional impairment in daily living, after diagnosis with this effect partly mediated by impaired cognitive function. We also show for the first time that, education before diagnosis was protective against impairments in daily living after diagnosis via better cognitive function and lower anxiety before diagnosis. Therefore, improving cognitive function and managing anxiety may dampen the impact of social deprivation and low educational attainment on poor health and help to promote independence in patients with osteoarthritis.

\section{Background}

The relationship between cognitive function and pain is well established, with good cognitive function protective against pain and pain associated with cognitive impairment (1-4). Furthermore, educational attainment has been shown to correlate with genes involved in osteoarthritis (5), and links between anxiety, heightened pain and impaired activities of daily living in osteoarthritis have been shown (6-10). However, the role of social deprivation, defined as social isolation and lack of social support (11), and the early inter-play of social, affective and cognitive factors, before a diagnosis of osteoarthritis, on subsequent patient outcomes, such as pain, independence and cognitive decline, is not understood. As these factors (e.g., anxiety) are influenced by the experience of pain, to show the unconfounded effects on subsequent pain and impairments, it is necessary to assess these prior to disease associated with pain (osteoarthritis). This would allow us to identify factors that 
could be the target of early interventions to reduce the costly disability caused by osteoarthritis (12). We used data from four different time points from the Survey of Health, Ageing and Retirement in Europe (SHARE), a large longitudinal survey covering 28 European countries (13) and we carefully selected a sample of newly diagnosed osteoarthritis patients to avoid confounding caused by diagnosis. We assessed the role of social deprivation, anxiety and cognitive function before a diagnosis of osteoarthritis on independence, pain and cognitive function after the onset of osteoarthritis.

\section{Social deprivation}

Social deprivation impacts pain (14-17), as well as cognitive decline $(18,19)$. However, the mechanisms underlying the link between social deprivation and impairments in activities of daily living are not well understood. It has been shown, that social engagement due to continued stimulation inhibits atrophy in cognitive abilities and promotes independence in old age (20-23), whereas lacking social support makes us more susceptible to disease $(24,25)$. Here, we tested for the first time how social deprivation, assessed before osteoarthritis diagnosis, impacts cognitive function, pain and independence in daily living following diagnosis. We aimed to disentangle the links between social deprivation, cognitive function, educational attainment and anxiety, before diagnosis, and how these impact pain and independence following diagnosis.

\section{Methods}

\section{Study population}

Data were taken from waves 4 (2011/2012) $(26,27), 5(2013)(28,29), 6(2015)(30,31)$ and $7(2019)(32,33)$ of the SHARE study, a multidisciplinary, cross-national, and longitudinal research project focusing on community dwelling adults aged 50 or older (13). Detailed information about the entire SHARE project is available atwww.share-project.org. SHARE respondents were included in our sub sample if: (a) they did not report a diagnosis of dementia, Alzheimer's, senility or Parkinson's; (b) they had participated in wave 5; (c) they reported a diagnosis of osteoarthritis between wave 5 and 6 (2013-2015); (d) they did not report a diagnosis of osteoarthritis at wave 5 ; (e) they reported a diagnosis at wave 7 (Figure 1). Osteoarthritis diagnosis was assessed at all waves with the following question: "Has a doctor ever told you that you had/Do you currently have: Osteoarthritis? (With this we mean that a doctor has told you that you have this condition, and that you are either currently being treated for or bothered by this condition.)"(29).

\section{Variables}

\section{Cognitive function}

Cognitive function was assessed at all waves and was based on multiple items: (1) immediate recall (participants were presented a list of 10 words and asked to repeat the words immediately; range $=0-10),(2)$ delayed recall (participants were asked for the list of 10 words after a delay; range $=0-10$ ), (3) subtraction (participants were asked to mentally solve a subtraction task; range $=0-5$ ), and (4) verbal fluency (participants were asked to produce as many animal names as possible within a given period of time; range $=0-100)$. A joint scale was created based on all items with a total score range of 0 to 125 (Cronbach's alpha $=0.80$, for wave 5 
and Cronbach's alpha $=0.76$, for wave 6 ). The higher the score, the higher the participant's cognitive function (34). We decided not use a standardised score of cognitive function due to the risks associated with their use in the analysis of longitudinal data $(35,36)$.

\section{Pain}

Pain was constructed from two questions asked at all waves of the survey. Participants were asked whether they had been troubled by pain (yes/no). Those who replied positively were then asked to rate how bad their pain was most of the time (either mild, moderate or severe). The two variables were added to create a single score ranging from 1 (not troubled by pain) to 4 (troubled by severe pain), representing whether respondents were troubled by pain and how severe it was. This verbal rating scale have been used widely in the pain literature (37).

\section{Anxiety}

In SHARE wave 5, five items were used to measure severity of anxiety that were taken from the Beck Anxiety Inventory (38). The respondents were asked about anxiety symptoms ("I had fear of the worst happening", "I was nervous", and "I had a fear of dying", "I felt my hands trembling", "I felt faint") they experienced in the last 7 days and answer on a four point Likert scale ("never", "hardly ever", "some of the time", "most of the time"). We created a single anxiety scale by adding the scores of all five items to obtain an overall score, with higher scores indicating higher anxiety (Cronbach's alpha $=0.69$ ).

\section{Social deprivation index}

A social deprivation index was provided in wave 5 of SHARE and was constructed using a battery of 15 questions related to participation in everyday life, social activities and the quality of the neighbourhood following Chakravarty and D'Ambrosio (39) and Levitas, Pantazis (11). In order to combine different social deprivation items into a single index, the authors computed the weight of each item based on a regression of the chosen items on the reported values of life satisfaction (40). The most important elements of the index, i.e. those with the highest weight are: feeling left out of things, not feeling part of the neighbourhood, having no helpful people in the local area and waiting too long to see a doctor (40).

\section{Instrumental activities of daily living (IADL)}

A modified version of IADL (41) was used in SHARE (42). IADL included seven activities in wave 5: "using a map to get around in a strange place", "preparing a hot meal", "shopping for groceries", "making telephone calls", "taking medications", "doing work around the house or garden" and "managing money" with a total score ranging from 0 to 7. Two more items were added in waves 6 and 7: "leaving the house independently and accessing transportation services", and "doing personal laundry", resulting in nine items in total (score: 0-9). A higher index score indicates more difficulty with these activities and lower mobility of the respondent (Cronbach's alpha $=0.71,0.80$ and 0.86 , for waves 5,6 and 7 , respectively).

\section{Additional variables}

Other variables included age ( $>40$ y.o.), gender, education measured with the International Standard Classification of Education (ISCED-97) (43), body mass index (BMI), smoking status (Currently smoking, Ex- 
smoker, Never smoked, and No response), alcohol consumption (How many drinks in 3 months), physical inactivity (Never moderate or vigorous activity and Other), number of chronic diseases (0-9), and marital status (Married and living together, Divorced, Widowed, and Other).

\section{Statistical analysis}

Modelling was performed using R version 4.0.1. For path analysis the 'lavaan' package was used (44). The missing mechanism of the SHARE data is assumed to be missing at random and the level of dropout in this subsample is small (17.1\%), thus, missing data were handled using full information maximum likelihood estimation (FIML). We conducted sensitivity analyses using multiple imputations $(m=40)$. No significant differences between the two methods for handling missing data were found (see Additional File 1).

Crossed-lagged path analysis was run using the pain and cognitive function measurements at waves 5 and 6 and IADL at waves 5, 6 and 7 . The model was constructed such that pain levels, cognitive function, and IADL each predicted each at the following wave. Path model was adjusted for age, sex, education level, number of chronic diseases, BMI and alcohol consumption at baseline (See Supplementary Table 7, Additional File 1 for correlational analyses).

Model fit was assessed using the Comparative Fit Index (CFI), the Tucker Lewis Index (TLI), the Root Mean Square Error of Approximation (RMSEA) and the Standardised Root Mean Square Residual (SRMR). To determine acceptable fit we used the cut-off criteria proposed by (45), who recommended that an RMSEA lower than .06 and CFI and TLI greater than .95 .

\section{Results}

\section{Descriptives}

Descriptive statistics for the sample are reported in Table 1. All fit indices suggested the model fits these data well (RMSEA $=0.038,95 \% \mathrm{Cl}$ 0.028-0.048, SRMR $=0.021, \mathrm{CFI}=0.987, \mathrm{TLI}=0.960)($ See Supplementary Table 1 , Additional File 1).

\section{Direct Effects}

The significant relationships are highlighted in the path model in Figure 2 (for all outcomes of our analysis, See Supplementary Table 2, Additional File 1). The main finding was that social deprivation before diagnosis predicted higher pain levels and impaired cognitive function after diagnosis (wave 6). Increased pain and anxiety before diagnosis predicted more impairments in activities of daily living after diagnosis, whereas better cognitive function before diagnosis predicted less functional impairments in daily living after diagnosis. Better cognitive function at wave 6 predicted less impairments in activities of daily living at wave 7, whereas wave 5 anxiety predicted more limitations in activities of daily living at wave 7.

\section{Indirect Effects}

Looking at the indirect paths (Figure 2 and Table 2), social deprivation, before diagnosis, predicted impairments in activities of daily living, following diagnosis, through its negative effect on cognition (wave 5 social 
deprivation -> wave 6 cognition -> wave 7 IADL), suggesting that one mechanism underlying the link between social deprivation and impairments in daily living is via cognitive ability. Furthermore, higher educational attainment predicted better cognition, before and after diagnosis (wave 4 education -> wave 5 cognition -> wave 6 cognition). Looking at the total indirect effects, social deprivation before diagnosis predicted impairments in daily living following diagnosis via poor cognitive function and pain at the time of diagnosis. Higher educational attainment, prior to diagnosis, was protective against impairments in daily living after diagnosis via better cognitive function and reduced pain as well as via better cognitive function and lower anxiety at the wave before diagnosis (wave 5).

\section{Discussion}

We show for the first time, in a group of newly diagnosed osteoarthritis patients, that social deprivation before diagnosis predicted poorer cognitive function and higher pain levels after diagnosis. We also identified, for the first time, a link between social deprivation, prior to diagnosis, and more impairments in daily living following diagnosis that was mediated by impaired cognitive function at the time of diagnosis, suggesting cognitive function is a potential mechanism underlying the deprivation-functional impairment relationship. We demonstrated, again for the first time, that education, before diagnosis, was protective against impairments in daily living following diagnosis via better cognitive function and lower anxiety, as well as via better cognitive function and reduced pain at the wave before diagnosis.

The link between higher social deprivation and impaired activities of daily living and its mediation by lower cognitive function may be explained by the cognitive reserve theory. This theory suggests that continued stimulation of cognitive abilities, due to social engagement inhibits atrophy in these abilities and promotes independence in old age and is supported by previous research in humans (20-23). At the same time, both higher pain levels and impaired cognitive function might further reduce social participation and increase loneliness in seniors $(46,47)$, creating a vicious cycle.

It has been previously shown that low educational attainment is associated with higher pain levels and more functional disability (48) and there is a very strong relationship between risk of osteoarthritis and years of education seen in very large genetic studies $(5,49)$. Furthermore, education is an important determinant of cognitive function in old age (50). However, the pathways linking these factors in osteoarthritis are unknown. We found for the first time that education was protective against impairments in activities of daily living via both improved cognitive function and lower anxiety, as well as improved cognitive function and reduced pain levels. Bidirectional links between cognitive function and affect, as well as cognitive function and pain have been demonstrated previously $(4,51)$. However, we showed that these associations were influenced by previous educational attainment and that their interactions before diagnosis predicted activities vital to independence and self-care after diagnosis. Therefore, managing anxiety and potential problems with cognitive functioning early in the disease course has apparent clinical benefit in terms of independent living. Cognitive-based interventions, involving the education of pain processing and false beliefs about movement can result in substantial improvements in disability and performance (52-56), and should be considered as part of the arsenal of treatment options.

\section{Limitations}


It is important to acknowledge the limitations of this study. The observed impairments in activities of daily living might be due to comorbid conditions, rather than osteoarthritis. However, we controlled for number of chronic conditions in our analyses and adjusted for previous IADL at each wave. Same-source bias can arise from use of perception-based measures (social deprivation index). However, perceived measures usually serve as good proxies of actual measures, as they are often highly correlated (57). As we did not have information about arthritis severity, despite controlling on disease duration, respondents may had different levels of osteoarthritis pathology.

\section{Conclusion}

We show for the first time that social deprivation, before osteoarthritis diagnosis, predicts functional impairment in daily living, after diagnosis with this effect mediated by impaired cognitive function. We also show for the first time that, education before diagnosis was protective against impairments in daily living after diagnosis via better cognitive function and lower anxiety before diagnosis. Therefore, improving cognitive function and managing anxiety may dampen the impact of social deprivation and low educational attainment on poor health and may help to promote independence in patients with osteoarthritis.

\section{Abbreviations}

BMI: Body Mass Index

CFI: Comparative Fit Index

FIML: Full Information Maximum Likelihood estimation

IADL: Instrumental Activities of Daily Living

ISCED-97: International Standard Classification of Education

RMSEA: Root Mean Square Error of Approximation

SHARE: Survey of Health, Ageing and Retirement in Europe

SRMR: Standardised Root Mean Square Residual

TLI: Tucker Lewis Index

\section{Declarations}

\section{Ethics approval and consent to participate}

The SHARE data collection procedures are subject to continuous ethics review. SHARE-ERIC's activities related to human subjects research are guided by international research ethics principles such as the Respect Code of Practice for Socio-Economic Research and the 'Declaration of Helsinki'.

\section{Consent for publication}




\section{Availability of data and materials}

The datasets used and/or analysed during the current study are available from the corresponding author on reasonable request.

\section{Competing interests}

The authors declare that they have no competing interests.

\section{Funding}

This work was part of a PhD project funded the National Institute of Health Research via the NIHR Nottingham Biomedical Research Centre.

\section{Authors' contributions}

$A K$ is the primary author and analysed the data. AMV is the main supervisor. EF and TB are secondary supervisors. AMV and EF provided guidance throughout all stages of data analysis. All authors were major contributors in writing the manuscript.

\section{Acknowledgements}

This paper uses data from SHARE Waves 4, 5, 6 and 7

(DOIs: 10.6103/SHARE.w4.710, 10.6103/SHARE.w5.710, 10.6103/SHARE.w6.710, 10.6103/SHARE.w7.710), see Börsch-Supan, Brandt (13) for methodological details.

The SHARE data collection has been funded by the European Commission through FP5 (QLK6-CT-2001-00360), FP6 (SHARE-I3: RII-CT-2006-062193, COMPARE: CIT5-CT-2005-028857, SHARELIFE: CIT4-CT-2006-028812), FP7 (SHARE-PREP: GA N²11909, SHARE-LEAP: GA N²27822, SHARE M4: GA N²61982, DASISH: GA N²83646) and Horizon 2020 (SHARE-DEV3: GA N676536, SHARE-COHESION: GA N870628, SERISS: GA N654221, SSHOC: GA N ${ }^{\circ}$ 823782) and by DG Employment, Social Affairs \& Inclusion. Additional funding from the German Ministry of Education and Research, the Max Planck Society for the Advancement of Science, the U.S. National Institute on Aging (U01_AG09740-13S2, P01_AG005842, P01_AG08291, P30_AG12815, R21_AG025169, Y1-AG4553-01, IAG_BSR06-11, OGHA_04-064, HHSN271201300071C) and from various national funding sources is gratefully acknowledged(see www.share-project.org).

\section{References}

1. Berryman C, Stanton TR, Bowering JK, Tabor A, McFarlane A, Moseley LG. Evidence for working memory deficits in chronic pain: A systematic review and meta-analysis. PAIN. 2013;154(8):1181-96. 
2. Attal N, Masselin-Dubois A, Martinez V, Jayr C, Albi A, Fermanian J, et al. Does cognitive functioning predict chronic pain? Results from a prospective surgical cohort. Brain. 2014;137(3):904-17.

3. Moriarty O, McGuire BE, Finn DP. The effect of pain on cognitive function: A review of clinical and preclinical research. Progress in Neurobiology. 2011;93(3):385-404.

4. James RJE, Ferguson E. The dynamic relationship between pain, depression and cognitive function in a sample of newly diagnosed arthritic adults: a cross-lagged panel model. Psychological Medicine. 2019:1-9.

5. Zengini E, Hatzikotoulas K, Tachmazidou I, Steinberg J, Hartwig FP, Southam L, et al. Genome-wide analyses using UK Biobank data provide insights into the genetic architecture of osteoarthritis. Nature genetics. 2018;50(4):549-58.

6. Burston JJ, Valdes AM, Woodhams SG, Mapp PI, Stocks J, Watson DJG, et al. The impact of anxiety on chronic musculoskeletal pain and the role of astrocyte activation. Pain. 2019;160(3):658-69.

7. Akin-Akinyosoye K, Frowd N, Marshall L, Stocks J, Fernandes GS, Valdes A, et al. Traits associated with central pain augmentation in the Knee Pain In the Community (KPIC) cohort. Pain. 2018;159(6):1035-44.

8. Stamm TA, Pieber K, Crevenna R, Dorner TE. Impairment in the activities of daily living in older adults with and without osteoporosis, osteoarthritis and chronic back pain: a secondary analysis of population-based health survey data. BMC Musculoskelet Disord. 2016;17:139.

9. Nur H, Sertkaya BS, Tuncer T. Determinants of physical functioning in women with knee osteoarthritis. Aging clinical and experimental research. 2018;30(4):299-306.

10. Sinikallio SH, Helminen EE, Valjakka AL, Väisänen-Rouvali RH, Arokoski JP. Multiple psychological factors are associated with poorer functioning in a sample of community-dwelling knee osteoarthritis patients. Journal of clinical rheumatology : practical reports on rheumatic \& musculoskeletal diseases. 2014;20(5):261-7.

11. Levitas R, Pantazis C, Fahmy E, Gordon D, Lloyd E, Patsios D. The Multi-Dimensional Analysis of Social Exclusion. 2007.

12. Neogi T. The epidemiology and impact of pain in osteoarthritis. Osteoarthritis and cartilage. 2013;21(9):1145-53.

13. Börsch-Supan A, Brandt M, Hunkler C, Kneip T, Korbmacher J, Malter F, et al. Data Resource Profile: The Survey of Health, Ageing and Retirement in Europe (SHARE). International Journal of Epidemiology. 2013;42(4):992-1001.

14. Jordan KP, Thomas E, Peat G, Wilkie R, Croft P. Social risks for disabling pain in older people: A prospective study of individual and area characteristics. Pain. 2008;137(3):652-61.

15. Rijk L, Kortlever JTP, Bandell DLJI, Zhang J, Gallagher SM, Bozic KJ, et al. The impact of socioeconomic status and social deprivation on musculoskeletal limitations. Journal of Orthopaedics. 2020;22:135-42.

16. Kiadaliri AA, Gerhardsson de Verdier M, Turkiewicz A, Lohmander LS, Englund M. Socioeconomic inequalities in knee pain, knee osteoarthritis, and health-related quality of life: a population-based cohort study in southern Sweden. Scandinavian journal of rheumatology. 2017;46(2):143-51.

17. Luong M-LN, Cleveland RJ, Nyrop KA, Callahan LF. Social determinants and osteoarthritis outcomes. Aging health. 2012;8(4):413-37.

18. Read S, Comas-Herrera A, Grundy E. Social Isolation and Memory Decline in Later-life. The Journals of Gerontology: Series B. 2019;75(2):367-76. 
19. Shankar A, Hamer M, McMunn A, Steptoe A. Social isolation and loneliness: relationships with cognitive function during 4 years of follow-up in the English Longitudinal Study of Ageing. Psychosomatic medicine. 2013;75(2):161-70.

20. Stern Y. Cognitive reserve in ageing and Alzheimer's disease. Lancet Neurol. 2012;11(11):1006-12.

21. Carlson MC, Saczynski JS, Rebok GW, Seeman T, Glass TA, McGill S, et al. Exploring the effects of an "everyday" activity program on executive function and memory in older adults: Experience Corps ${ }^{\circledR}$. The Gerontologist. 2008;48(6):793-801.

22. Carlson MC, Kuo JH, Chuang Y-F, Varma VR, Harris G, Albert MS, et al. Impact of the Baltimore Experience Corps Trial on cortical and hippocampal volumes. Alzheimers Dement. 2015;11(11):1340-8.

23. Fried LP, Carlson MC, McGill S, Seeman T, Xue Q-L, Frick K, et al. Experience Corps: a dual trial to promote the health of older adults and children's academic success. Contemp Clin Trials. 2013;36(1):1-13.

24. Kaplan GA, Salonen JT, Cohen RD, Brand RJ, Syme SL, Puska P. Social connections and mortality from all causes and from cardiovascular disease: prospective evidence from eastern Finland. Am J Epidemiol. 1988;128(2):370-80.

25. Wilkinson RG, Marmot M. Social determinants of health: the solid facts: World Health Organization; 2003.

26. Börsch-Supan A. Survey of Health, Ageing and Retirement in Europe (SHARE) Wave 4. In: SHARE-ERIC, editor. 7.1.0. ed2020.

27. Abduladze L, Börsch-Supan A. SHARE wave 4: innovations \& methodology2013.

28. Börsch-Supan A. Survey of Health, Ageing and Retirement in Europe (SHARE) Wave 5. Release version: 6.0. 0. SHARE-ERIC. Data set. 2020;10.

29. Börsch-Supan A, Malter F. SHARE Wave 5: Innovations \& Methodology. Mannheim: MEA. 2015.

30. Börsch-Supan A. Survey of Health, Ageing and Retirement in Europe (SHARE) Wave 6. In: SHARE-ERIC, editor. Data set. 7.1.0 ed2020.

31. Malter F, Börsch-Supan A. SHARE wave 6: panel innovations and collecting dried blood spots. Munich: Munich Center for the Economics of Aging (MEA). 2017.

32. Börsch-Supan A. Survey of Health, Ageing and Retirement in Europe (SHARE) Wave 7. In: SHARE-ERIC, editor. Data set. 7.1.0 ed2020.

33. Bergmann M, Scherpenzeel A, Börsch-Supan A. Share Wave 7 Methodology: Panel innovations and life histories. Munich: Munich Center for the Economics of Aging and the Max Planck Institute for Social Law and Social Policy. 2019.

34. Portellano-Ortiz C, Conde-Sala JL. Cognition and its association with the factors of the EURO-D: Suffering and Motivation. Findings from SHARE Wave 6. International Journal of Geriatric Psychiatry. 2018;33(12):1645-53.

35. Little TD. Longitudinal structural equation modeling: Guilford press; 2013.

36. Moeller J. A word on standardization in longitudinal studies: don't. Frontiers in Psychology. 2015;6(1389).

37. Breivik H, Borchgrevink PC, Allen SM, Rosseland LA, Romundstad L, Breivik Hals EK, et al. Assessment of pain. British Journal of Anaesthesia. 2008;101(1):17-24.

38. Beck AT, Steer R. Beck anxiety inventory (BAI). Überblick über Reliabilitäts-und Validitätsbefunde von klinischen und außerklinischen Selbst-und Fremdbeurteilungsverfahren. 1988:7. 
39. Chakravarty SR, D'Ambrosio C. THE MEASUREMENT OF SOCIAL EXCLUSION. Review of Income and Wealth. 2006;52(3):377-98.

40. Michał M, Mateusz N, Monika O. 6. Measuring social deprivation and social exclusion Ageing in Europe - Supporting Policies for an Inclusive Society. Berlin, Boston: De Gruyter; 2015. p. 67-78.

41. Lawton MP, and Brody, E.M. Assessment of older people: Self-maintaining and instrumental activities of daily living. Gerontologist. 1969;9:179-86.

42. Mehrbrodt T, Gruber S, Wagner M. Scales and multi-item indicators. Munich, Germany: Survey of Health, Ageing and Retirement in Europe. 2017.

43. United Nations Educational S, Organization. C. ISCED 1997: International Standard Classification of Education (Re-Edition. Author Paris; 2006.

44. Rosseel Y. Lavaan: An R package for structural equation modeling and more. Version 0.5-12 (BETA). Journal of statistical software. 2012;48(2):1-36.

45. Hu L-t, Bentler PM. Cutoff criteria for fit indexes in covariance structure analysis: Conventional criteria versus new alternatives. Structural Equation Modeling. 1999;6(1):1-55.

46. James RJE, Walsh DA, Ferguson E. General and disease-specific pain trajectories as predictors of social and political outcomes in arthritis and cancer. BMC Medicine. 2018;16(1):51.

47. Cacioppo JT, Hawkley LC. Perceived social isolation and cognition. Trends in cognitive sciences. 2009;13(10):447-54.

48. Atlas SJ, Skinner J. Education and the prevalence of pain. Research findings in the economics of aging: University of Chicago Press; 2010. p. 145-66.

49. Tachmazidou I, Hatzikotoulas K, Southam L, Esparza-Gordillo J, Haberland V, Zheng J, et al. Identification of new therapeutic targets for osteoarthritis through genome-wide analyses of UK Biobank data. Nat Genet. 2019;51(2):230-6.

50. Olivera J, Andreoli F, Leist AK, Chauvel L. Inequality in old age cognition across the world. Economics \& Human Biology. 2018;29:179-88.

51. Gale CR, Allerhand M, Deary IJ. Is there a bidirectional relationship between depressive symptoms and cognitive ability in older people? A prospective study using the English Longitudinal Study of Ageing. Psychological Medicine. 2012;42(10):2057-69.

52. Koes BW, van Tulder MW, van der Windt WM, Bouter LM. The efficacy of back schools: a review of randomized clinical trials. J Clin Epidemiol. 1994;47(8):851-62.

53. Nijs J, Meeus M, Cagnie B, Roussel NA, Dolphens M, Van Oosterwijck J, et al. A modern neuroscience approach to chronic spinal pain: combining pain neuroscience education with cognition-targeted motor control training. Phys Ther. 2014;94(5):730-8.

54. Louw A, Diener I, Butler DS, Puentedura EJ. The effect of neuroscience education on pain, disability, anxiety, and stress in chronic musculoskeletal pain. Arch Phys Med Rehabil. 2011;92(12):2041-56.

55. Moseley GL, Nicholas MK, Hodges PW. A randomized controlled trial of intensive neurophysiology education in chronic low back pain. Clin J Pain. 2004;20(5):324-30.

56. Pelletier R, Higgins J, Bourbonnais D. Is neuroplasticity in the central nervous system the missing link to our understanding of chronic musculoskeletal disorders? BMC Musculoskeletal Disorders. 2015;16(1):25. 
57. Curry A, Latkin C, Davey-Rothwell M. Pathways to depression: The impact of neighborhood violent crime on inner-city residents in Baltimore, Maryland, USA. Social Science \& Medicine. 2008;67(1):23-30.

\section{Tables}

Table 1. Descriptive statistics $(n=1,240)$ 


\begin{tabular}{|c|c|c|c|c|}
\hline Characteristics & W4 & W5 & W6 & W7 \\
\hline Age & $66.65(9.17)$ & $68.65(9.17)$ & $70.65(9.17)$ & $72.65(9.17)$ \\
\hline BMI & $27.69(5.10)$ & $27.34(6.17)$ & $27.04(6.94)$ & $26.92(7.03)$ \\
\hline No. of chronic diseases & $2.05(1.54)$ & $1.88(1.50)$ & $3.03(1.63)$ & $3.12(1.69)$ \\
\hline Social deprivation index ${ }^{1}$ & - & $0.18(0.14)$ & - & - \\
\hline Cognition total score & $34.46(10.56)$ & $34.86(11.17)$ & $35.05(10.72)$ & * \\
\hline Level of pain & ** & $2.27(1.11)$ & $2.60(1.05)$ & * \\
\hline Anxiety ${ }^{1}$ & - & $7.87(2.82)$ & - & - \\
\hline IADL & $0.27(0.74)$ & $0.32(0.82)$ & $0.58(1.32)$ & $0.76(1.63)$ \\
\hline Female Gender, n (\%) & 72.25 & 72.26 & 72.26 & 72.26 \\
\hline \multicolumn{5}{|l|}{ Education, n (\%): } \\
\hline Low - ISCED code 0,1 and 2 & 41.00 & 40.24 & 40.16 & 40.08 \\
\hline Medium - ISCED code 3 and 4 & 37.75 & 37.63 & 37.71 & 37.50 \\
\hline High - ISCED code 5 and 6 & 21.15 & 21.55 & 21.55 & 21.62 \\
\hline Other & 0.60 & 0.57 & 0.57 & 0.56 \\
\hline \multicolumn{5}{|l|}{ Marital status, n (\%) } \\
\hline Married and living together & 64.25 & 50.00 & 45.07 & * \\
\hline Divorced or widowed & 28.50 & 45.00 & 49.29 & * \\
\hline Other & 7.18 & 5.00 & 11.27 & * \\
\hline \multicolumn{5}{|l|}{ Physical activity, n (\%) } \\
\hline Other & 90.28 & 88.47 & 87.02 & * \\
\hline Never vigorous or moderate & 9.72 & 11.45 & 12.98 & \\
\hline \multicolumn{5}{|l|}{ Alcohol consumption, $n$ (\%) } \\
\hline Not at all in the last 3 months & 74.23 & 71.01 & 82.18 & * \\
\hline Less than once a month & 14.30 & 15.02 & 7.98 & * \\
\hline Once or twice a month & 6.85 & 7.80 & 5.00 & * \\
\hline More than once or twice a month & 4.59 & 3.60 & 4.84 & * \\
\hline \multicolumn{5}{|l|}{ Smoking status, $\mathrm{n}(\%)$} \\
\hline Currently smoking & 15.61 & 12.93 & * & * \\
\hline Never smoked daily & 62.12 & 72.00 & * & * \\
\hline No, I have stopped & 22.27 & 15.07 & * & * \\
\hline
\end{tabular}




\section{Affective/emotional disorder ${ }^{2}, \mathrm{n}(\%)$}

At risk of severe deprivation ${ }^{1}, \mathrm{n}(\%)$

*It is not reported here due to more than $50 \%$ missing values in this variable.

** Pain intensity was not assessed in wave 4 of the SHARE. However, $75.56 \%$ participants reported being bothered by pain in back, knees, hips or other joint at wave 4 .

${ }^{1} / t$ was only measured at wave 5 of the SHARE

${ }^{2}$ It was not measured at wave 4 of the SHARE

Table 2. Indirect paths predicting pain at wave 6 and IADL at waves 6 and 7 and their total indirect effects 


\begin{tabular}{|llll|}
\hline Indirect paths & SD coefficient & S.E. & P \\
\hline W5A à W6CF à W7IADL & 0.001 & 0.001 & 0.512 \\
\hline W5A à W6P à W7IADL & 0.001 & 0.001 & 0.389 \\
\hline W4E à W5CF à W6CF & 0.036 & 0.017 & $0.035^{\star}$ \\
\hline W4E à W5CF à W6P & -0.004 & 0.002 & 0.108 \\
\hline W4Eà W5A à W6P & -0.002 & 0.002 & 0.325 \\
\hline W4E à W5CF à W6IADL & -0.003 & 0.002 & 0.140 \\
\hline W4E à W5SD à W6IADL & 0.000 & 0.001 & 0.919 \\
\hline W4E à W5P à W6IADL & -0.001 & 0.001 & 0.334 \\
\hline W4E à W5A à W6IADL & -0.004 & 0.003 & 0.125 \\
\hline W5SD à W6CF à W7IADL & 0.006 & 0.003 & $0.048 *$ \\
\hline W5SD à W6P à W7IADL & 0.002 & 0.002 & 0.331 \\
\hline Total indirect effects & SD coefficient & S.E. & P \\
\hline W5A à W6CF+W6P à W7IADL & 0.002 & 0.002 & 0.291 \\
\hline W4Eà W5CF+W5A à W6P & -0.005 & 0.003 & 0.052 \\
\hline W4E à W5P+W5SD à W6IADL & -0.001 & 0.002 & 0.481 \\
\hline W4E à W5CF+W5SD à W6IADL & -0.003 & 0.002 & 0.228 \\
\hline W4E à W5A+W5SD à W6IADL & -0.004 & 0.003 & 0.207 \\
\hline W4Eà W5CF+W5P à W6IADL & -0.004 & 0.002 & $0.043^{*}$ \\
\hline W4Eà W5CF+W5A à W6IADL & -0.007 & 0.003 & $0.032 *$ \\
\hline W4Eà W5P+W5A à W6IADL & -0.005 & 0.003 & 0.067 \\
\hline W5SD à W6CF+W6P à W7IADL & 0.008 & $0.023 *$ \\
\hline
\end{tabular}

W, wave; A, anxiety; E, education; P, pain; CF, cognitive function; SD, social deprivation; IADL, independent activities of daily living. ${ }^{*}=p<.05,{ }^{\star}=p<.01, * \star *=p<.001 . n=1,240$

Figures 
Participated in Wave 4 of the SHARE cohort

$$
\mathrm{n}=58,129
$$

Reported a diagnosis of osteoarthritis at Wave 6 of the SHARE cohort $(n=7,547)$

\section{Excluded:}

Participants with a diagnosis of dementia, Alzheimer's, senility, Parkinson's at waves 4 and 5

\section{Reported their}

diagnosis at Wave 6 and did not report a diagnosis at wave 5

$$
(n=3,180)
$$

\section{Respondents who} participated in Wave 7 of SHARE $(n=2,635)$ and reported a diagnosis $(n=1,240)$

Did not have missing data on all measurements of pain and cognitive function $(n=1,228)$

\section{Missing data accounted for using \\ Full Information Maximum Likelihood}

Figure 1

Flow chart of the assignment of respondents to the subsample analysed in this study. 

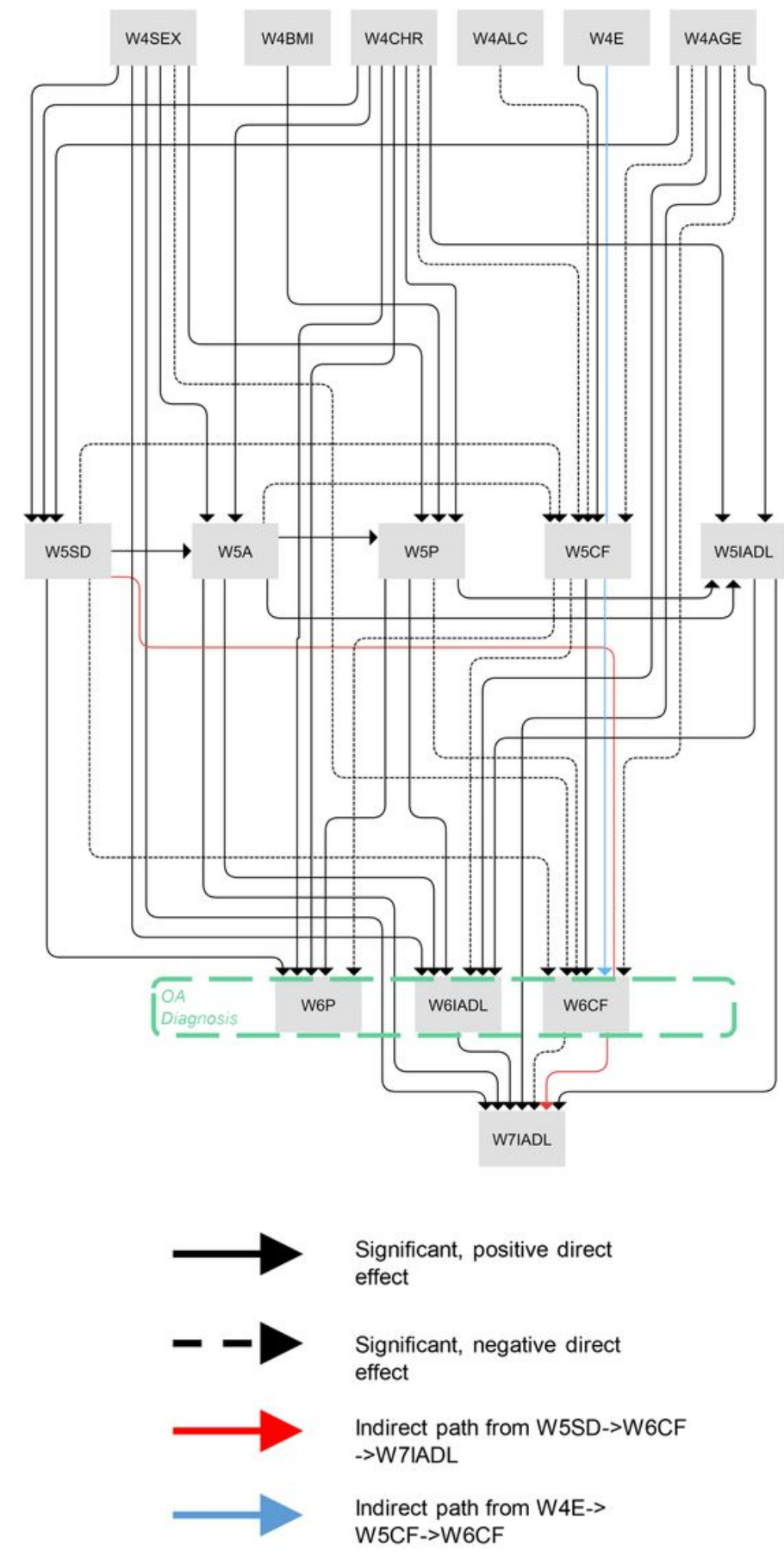

\section{Figure 2}

Path model of the significant direct and indirect relationships between pain (P) and cognitive function (CF) at waves 5 and 6 (W5 and W6) and instrumental activities of daily living (IADL) at waves 5 to 7 (W5, W6 and W7) of the SHARE, for participants who reported a diagnosis of osteoarthritis at W6 $(n=1,240)$. W5 anxiety (W5A), social deprivation (W5SD), W5P and W5CF predict W6P and W6CF and W5, W6 and W7 IADL. W5SD, W5A, W5IADL, W5P and W5CF were adjusted for age (AGE), gender (SEX), education (E), body mass index (BMI), number of diagnosed chronic diseases (CHR) and alcohol intake (ALC) at wave 4 (W4). 


\section{Supplementary Files}

This is a list of supplementary files associated with this preprint. Click to download.

- KourakiAdditionalFile.1.docx 